\title{
A review of recent studies on vortex-induced vibrations of long slender cylinders
}

\author{
Xiaodong $\mathrm{Wu}$, Fei Ge*, Youshi Hong \\ State Key Laboratory of Nonlinear Mechanics, Institute of Mechanics, Chinese Academy of Sciences, Beijing 100190, PR China
}

\section{A R T I C L E I N F O}

\section{Article history:}

Received 11 January 2011

Accepted 23 November 2011

Available online 23 December 2011

\section{Keywords:}

Long slender cylinder

Vortex-induced vibration

Dual resonance

Multi-mode vibration

Traveling wave

\begin{abstract}
A B S T R A C T
This paper reviews the progress made during the past decade on vortex-induced vibration (VIV) of long slender cylindrical structures. When the aspect ratio, which is defined as the ratio of length to diameter for cylindrical structures, is large enough $\left(10^{2}-10^{3}\right)$, some unexpected phenomena occur, e.g., dual resonance, multi-mode vibration, unsteady lock-in, the third and higher harmonic fluid forces and traveling wave dominant response, as summarized in this paper. In addition, a brief outline is given of numerical methods used in predicting the response of long slender cylinder undergoing VIV.
\end{abstract}

Crown Copyright @ 2011 Published by Elsevier Ltd. All rights reserved.

\section{Introduction}

In recent years, owing to the large demand of crude oil in the world, offshore oil and gas explorations have been moved to deeper water regions. Ocean structures such as extremely long risers operating at extremely deep water are plagued with vibration problems. Long slender cylinders are also the representative system for mooring tethers of Submerged Floating Tunnel (SFT) (Ge et al., 2008). These are several examples among a large number of cases where aspect ratio has a significant effect on VIV when the vibrating structure is not rigid.

VIV is a common phenomenon in many fields of engineering. The importance of VIV has led to a large number of studies summarized in the comprehensive reviews of Griffin and Ramberg (1982), Khalak and Williamson (1999), Blackburn et al. (2001), Sarpkaya (2004), Williamson and Govardhan (2004), Gabbai and Benaroya (2005), Sumner (2010), Bearman (2011) and in the book of Païdoussis et al. (2011). However, most of these reviews are focused on the VIV of short rigid cylinders, where the aspect ratio of the cylinders is usually smaller than $10^{2}$. The features of VIV of long slender cylinders have not been fully understood yet. For testing of long slender cylinders needs a large facility and relatively complicated instrumentation, thus only a few full-scale or large-scale experiments for this kind of model have been carried out.

When the vortex shedding frequency is close to one of the natural frequencies of the cylinder, large amplitude resonant response occurs, called as lock-in. Lock-in behavior in uniform flow was well documented in literature. However long slender cylinders in ocean engineering are often confronted with sheared flow; the occurrence of lock-in or synchronization in a sheared flow is complicated with the fact that the resonant responses at different axial locations may be in different modes and the excited modes compete with each other. Lock-in in a weakly sheared flow and in a highly sheared flow was observed by Vandiver (1993a) and Vandiver et al. (1996). For long slender cylinders in sheared flow, the response under lock-in is not stationary. Vandiver et al. (1996) proposed that, when lock-in occured, the mode might switch from one to another due to the fluctuation in the tension or flow. Lie et al. (1997) observed a sudden shift from the second mode

\footnotetext{
${ }^{*}$ Corresponding author. Tel.: +8610 82543968; fax: +861062561284

E-mail address: gefei@imech.ac.cn (F. Ge).
} 
lock-in to the third mode lock-in while VIV frequency remained unchanged. Chaplin et al. (2005a) observed a temporary mode transition of the response in a uniform flow. In many cases, the response often presents non-lock-in behavior. In these cases the spectrum of the response exhibits a peak at the shedding frequency, but with a broader bandwidth including the nearest natural frequencies (Kim et al., 1986).

A long slender cylinder with a series of natural frequencies may have different modes excited in in-line (IL) and crossflow (CF) directions since IL vibration excited by vortex shedding is at distinct frequency from that of CF vibration. When the natural frequency ratio (the ratio of natural frequency of IL excited mode to $\mathrm{CF}$ ) equals to the excitation frequency ratio (the ratio of IL excitation frequency to $\mathrm{CF}$ ), dual resonance occurs, which means the IL and CF motions resonate simultaneously. Experiments (Dahl et al., 2006, 2007,2010; Huera-Huarte and Bearman, 2009) showed that dual resonance is characterized by highly repeatable figure eight cylinder orbits, steady phase difference between IL and CF vibrations and the third harmonic in lift force.

The fact that IL vibration is at distinct frequency from that of CF vibration is well known for the short rigid cylinder VIV. Recently, the contribution from IL vibration to fatigue has been noticed for long slender cylinders (Baarholm et al., 2006; Trim et al., 2005). The third and fifth harmonics in CF direction were described in accelerometer measurements (Vandiver, 1993a). Recent field tests (Vandiver et al., 2009) on slender risers with very large aspect ratio (over 3000) showed that these higher harmonic strains, corresponded to very high vibrating modes, were found to be of the same order of magnitude as the strain related to the fundamental VIV frequency and quite important for VIV related fatigue damage. Such higher harmonics were also observed in laboratory experiments (Dahl et al., 2007; Jauvtis and Williamson, 2004).

For short rigid cylinders, which usually vibrate in low mode, standing wave behavior dominates the whole cylinders, whereas for long slender cylinders, both standing wave and traveling wave were observed in the field and laboratory experiments. Alexander (1981) and Vandiver (1993a) observed traveling wave responses for cables, Vanatta and Gharib (1987) observed similar wave behavior for cables with soft end supports. When the traveling wave reaches both ends of cylinder, reflection generates a local standing wave-like pattern, which attenuates rapidly with the distance from the end. Thus standing wave near the end and intermediate traveling wave co-exist on the cylinder. For very long cylinders, since the decay of wave reflected from both ends is so considerable that the standing wave formed by the reflection of wave is extremely weak, the responses are of traveling wave dominant pattern. Vandiver et al. (2009) conducted experiments on very long cylinders in ocean environment. They observed that in many cases the responses were dominated by the traveling wave, and the majority of the VIV energy was concentrated in the traveling wave region.

There have been very few methods for predicting VIV of long slender cylinders. Thus the methods for short cylinders are provisionally adopted to simulate the VIV of long cylinders. These methods are usually based on the experimental data of short cylinders. When these methods are used in predicting the VIV of long structures, the results are in great discrepancy compared with experimental data and therefore large safety factors are needed. Recently some progresses have been made toward the predicting VIV of long slender structures. In this paper the methods used in predicting VIV of long slender structures are briefly presented.

The behavior of VIV of long slender structures, which is extremely important for the safety of marine risers, mooring cables or other similar structures, are so different from those of short ones and thus they deserve more attention of researchers. This paper is organized as follows. First the characteristics of VIV of long slender cylinders are summarized. Then the methods used for predicting VIV of the long slender cylinders are reviewed. Finally future perspective for the study of VIV of long slender cylinders is discussed.

\section{Characteristics of VIV of long slender cylinders}

\subsection{Resonant responses of long slender cylinders}

\subsubsection{Multi-mode vibrations of long slender cylinders}

Lock-in is the most distinct feature of VIV and is observed in numerous laboratory experiments and flow simulations involving cables, cantilevers, bridge models and elastically held cylinders (Blackburn and Henderson, 1996; de Langre, 2006; Feng, 1968). Generally, lock-in is described as the ability of an elastic structure to control the shedding process in a bandwidth around its resonant frequency. When lock-in occurs, the amplitude of cylinders will increase significantly and the phase angle will have a jump (Fig. 1). For such a structure (Feng, 1968) with high mass ratio (the ratio of the mass per unit length of the cylinder to the mass of the displaced fluid), the frequency ratio $f_{\text {ex }} / f_{\text {air }}$ (ratio of vortex shedding frequency to natural frequency in air) is almost constant with increasing reduced velocity $U^{*}$ (defined as $U^{*}=U / f_{N} D$, where $U$ is the flow velocity, $f_{N}$ is the $N$ th natural frequency and $D$ is the cylinder outer diameter), thus the Strouhal law, which corresponds to the oblique line, will not be followed.

Short rigid cylinders possess well separated modal frequencies, which reduce the effects of modal interaction and cause single-mode lock-in to occur easily (Iwan and Jones, 1987). For long slender cylinders, which have many natural frequencies (Brika and Laneville, 1993) and as the frequency intervals between adjacent modes are very small, the cylinders are usually excited in multiple and higher modes. In this case, lock-in is defined as the single mode dominance, i.e. one mode has enough energy and prohibits competing modes from participating in the vibration (Vandiver et al., 1996). In many cases, no single mode dominates other competing modes, when non-lock-in occurs. Non-lock-in phenomenon was described in detail by Kim et al. (1986). 


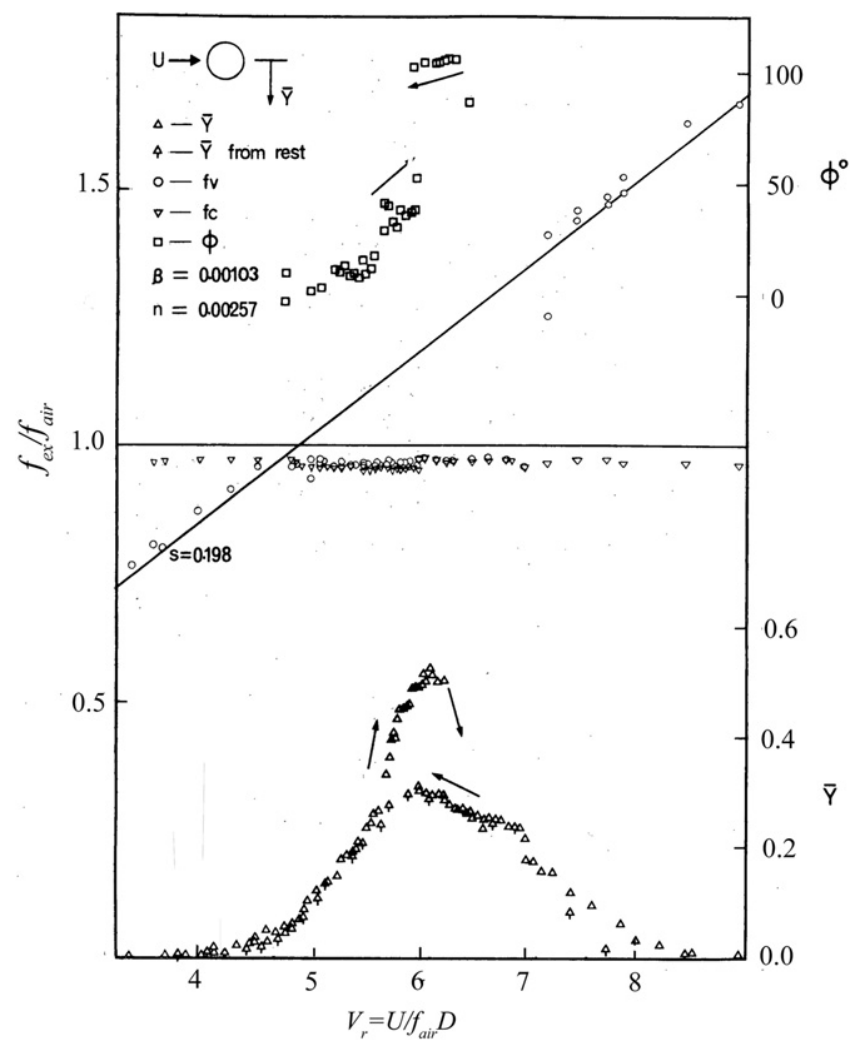

Fig. 1. Response and wake characteristics of a spring-mounted cylinder freely oscillating in air (Feng, 1968).

Generally VIV response under lock-in in laboratory experiments is dominated by standing wave behavior, with distinct nodes and antinodes (Tognarelli et al., 2004). In this case, the structures are characterized by their mode shapes with standing waves in space. When single-mode lock-in occurs, the VIV response is at a single frequency and in a single standing wave mode shape. The multi-mode response can be regarded as the superposition of individual modes; each mode corresponds to a standing wave mode shape at distinct frequency. However, for long slender cylinders with large aspect ratio in sheared current, the response is generally in traveling waves.

Model tests give better understanding for multi-mode behavior of long slender cylinders (Tognarelli et al., 2004). These tests, vibrating at high order mode, are featured with complicate and expensive apparatus, which makes the implementation of model tests of long slender cylinders rather difficult. In these tests, the strain generally serves as the primary source of response, partly because it is related directly to the structure fatigue. Acceleration or displacement is considered as an auxiliary measured quantity. High sampling rates and careful time synchronization are required for the measurement systems. Besides, the distribution of sensors should be chosen carefully. The goal of the model design is to allow the measured response to reveal important characteristics over the range of flow speeds, for example, careful selection of material properties and top tensions ensures the occurrence of required high vibration modes. In addition, test apparatus, such as the boundary constraints of model, and generation of well defined flow field in water tank should also be considered with great care.

Owing to the large aspect ratio of the model, these tests are generally carried out in large-scale water tanks or ocean environment. Tognarelli et al. (2004) performed VIV test on a riser with $9.63 \mathrm{~m}$ in length, and $20 \mathrm{~mm}$ in diameter in Marine Technology Research Institute (MARINTEK). Their model was equipped with dense strain and acceleration sensors to obtain more detail of VIV. The excited modes were up to 8 in CF direction and 12 in IL direction. Trim et al. (2005) conducted a series of tests on a flexible riser model of $38 \mathrm{~m}$ in length, and $0.027 \mathrm{~m}$ in diameter. These tests were performed in uniform and sheared flow and the riser was excited up to the 16th mode in CF direction. Lie and Kaasen (2006) conducted a test for a model of $90 \mathrm{~m}$ in length, and $0.03 \mathrm{~m}$ in diameter exposing to sheared flow. The IL excited mode was up to 50. Chaplin et al. (2005a) employed an apparatus with vertical placed cylinder in uniform flow. The lower portion of the cylinder was submerged in water flume, whereas the upper portion was in still water. This layout allowed the employment of cylinders with larger length while the depth of the water flume was limited. Similar apparatus was used in the experiment of Huera-Huarte and Bearman (2009, 2011) and Huera-Huarte and Gharib (2011a, 2011b). Recently, Vandiver et al. (2009) conducted a series of experiments on slender risers with aspect ratio over 3000 in Gulf Stream. Very high modes were excited in their experiments. 


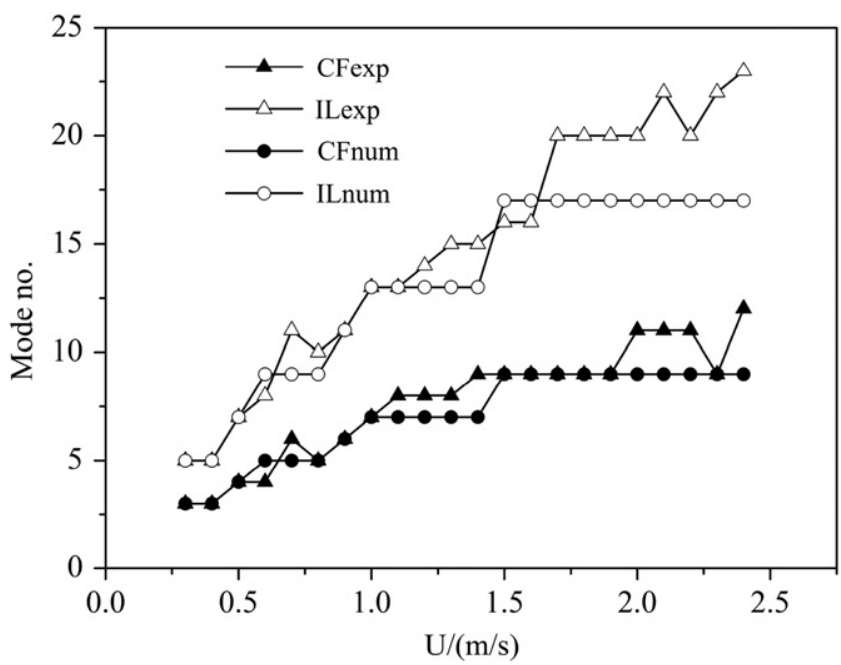

Fig. 2. The dominant mode of riser vibration versus towing speed. Circular symbols represent simulation results and triangle symbols represent experimental data (Ge et al., 2009).

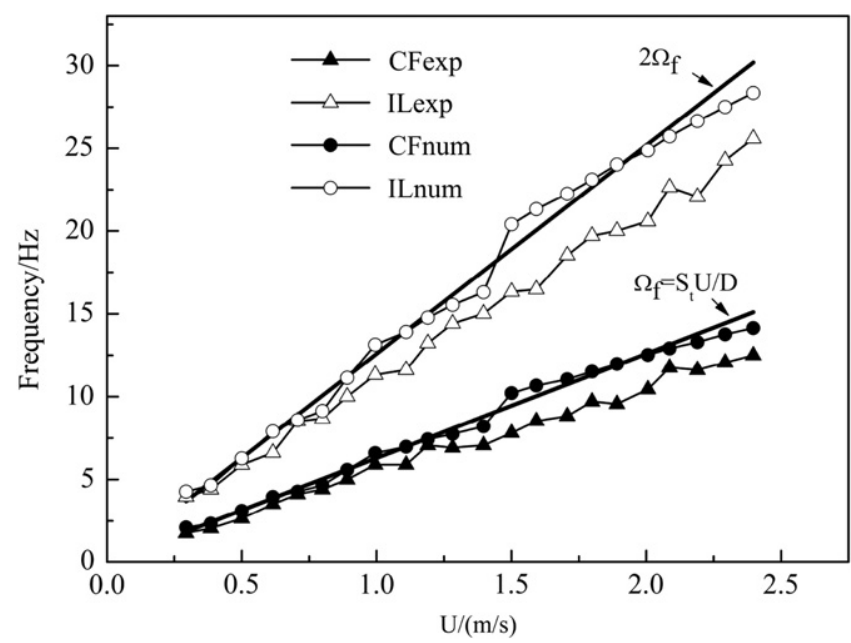

Fig. 3. Dominant mode frequency of riser vibration versus towing speed. Circular symbols represent simulation results and triangle symbols represent experimental data (Ge et al., 2009).

Ge et al. (2009) showed that, for a long slender cylinder, the natural frequencies are close to one another. When the flow velocity changes, the resonant response switches from one natural frequency to another. Figs. 2 and 3 show the dominant mode and dominant mode frequency varying with the flow velocity, respectively. Chaplin et al. (2005a) also described the change of the dominant mode frequency.

The dynamic features of long slender cylinders are determined by the tension and bending stiffness. Depending on whether they are tension dominated or not, the cylinders exhibit dynamic characteristics similar to tensioned strings or untensioned beams. The natural frequencies of an untensioned beam and a tensioned string are, respectively, given by

$$
\begin{aligned}
& f_{n, \text { string }}=n \frac{1}{2} \sqrt{\frac{T}{m L^{2}}}, \\
& f_{n, \text { beam }}=n^{2} \frac{\pi}{2} \sqrt{\frac{E I}{m L^{4}}},
\end{aligned}
$$

where $n$ is the mode order, $T$ is the tension, $E I$ is the bending stiffness and $m=m_{s}+m_{a}$ is the sum of the structure mass and the fluid added mass. The natural frequency of a tensioned cylinder is a combination of both above-mentioned. Baarholm et al. (2006) noticed that for lower modes, the natural frequency of the tensioned riser behaved as in the tensioned string case, while it was close to the untensioned beam case for higher modes. For the experimental model of Lee and Allen 
(2010), the tension was adjustable and varied as the flow velocity; meanwhile the bending stiffness remained the same. When lock-in occurs and the model is tension dominated, the vibration frequency of the model increases almost linearly with flow velocity. However, if the model is bending stiffness dominated, the vibration frequency will exhibit a stepped increase with the flow velocity. In addition, the tension or bending stiffness has a significant influence on some typical features of VIV, such as response branches. In the experiment of Huera-Huarte and Bearman (2009), three different top tensions were adopted. In the smallest tension case, the initial, lower and upper branches were definitely observed in the dynamic response of the model, whereas for the other tension cases, the lower branch of dynamic response vanished.

\subsubsection{Resonance for long slender cylinders in sheared flow}

In ocean environment, long slender cylinders are exposed to sheared flow over the length. In sheared flow, different modes are excited at different locations along the length of cylinder and each mode could be a potential factor, which influences the entire dynamic character of the cylinder. The response of the cylinder at any location along its length is seen as the superposition of each mode with corresponding participation factor. Thus in sheared flow, lock-in is defined as the circumstance in which the single mode dominates the response, whereas other modes are suppressed (Marcollo and Hinwood, 2006; Vandiver et al., 1996).

Vandiver et al. (1996) presented two dimensionless parameters, which could be used to predict the occurrence of lockin under the sheared flow condition. One is the number of potential modes within vortex shedding bandwidth and the other is the shear fraction, i.e. the ratio of variation of velocity to averaged velocity. Non-lock-in is highly probably to occur when the two parameters fall in "U" region (Fig. 4), beyond this region lock-in is more likely to happen. Marcollo and Hinwood (2006) observed that, in sheared flow, the response of the cylinder might vary from lock-in to non-lock-in, multimode behavior and IL motion was very important for predicting the CF lock-in. In the experiment of Lie and Kaasen (2006), lock-in phenomenon was not observed in well defined sheared flow and the responses were abundant in participating modes and frequency components. Vandiver et al. (1996) suggested that in the case of non-lock-in, several modes participate in the vibration and no one mode can prevent competing mode from interacting with wake. Lock-in in sheared flow condition was also discussed by Bourguet et al. (2011). Generally the total root mean square (RMS) responses in the case of non-lock-in were remarkably lower than those in single-mode lock-in cases (Vandiver et al., 1996).

\subsubsection{Dual resonance for long slender cylinders}

The study by Dahl et al. (2010) has shown that, when the nominal frequency ratio (ratio of IL natural frequency in air to $\mathrm{CF}$ ) is close to 2, the dual resonance is bound to occur. Sarpkaya (1995) reported the experimental results associated with a cylinder with a nominal frequency ratio of 2 . In his study, dual resonance of a rigid cylinder took place, and it is worth noticing that the CF response exhibited two peaks. Sarpkaya (1995) also gave other results for the nominal frequency ratios from 1 to 2 . When the nominal frequency ratio equaled 1 , the peak response was observed at a higher reduced velocity compared with the case with only CF motion. Dahl et al. $(2006,2007)$ performed tests for six frequency ratios, and similar results with those of Sarpkaya (1995) were obtained. Dahl et al. (2010) found that under dual resonance, the actual frequency ratio of the cylinder will be altered to 2, although the nominal frequency ratio does not exactly equal 2 . When dual resonance occurs, figure eight cylinder orbits, steady phase difference between IL and CF vibrations and the third harmonic in lift force would be expected to appear. Dahl et al. (2006) showed the cylinder orbit shapes under these six frequency ratios. Additional studies by Jeon and Gharib (2001), Sanchis et al. (2008) and Blevins and Coughran (2009) showed that the dual resonance is accompanied by steady figure eight cylinder orbits.

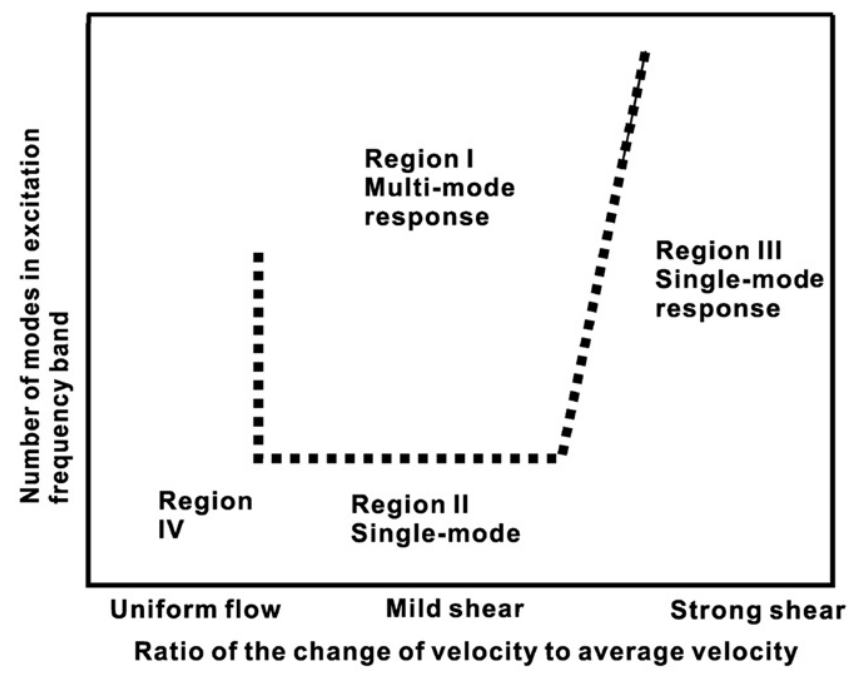

Fig. 4. Identification of lock-in (single mode) and multi-mode regions (Vandiver et al., 1996). 
The above studies were focused on short rigid cylinders. Steady figure eight orbits are also found in VIV of long slender cylinders. Huera-Huarte and Bearman (2009) found when dual resonance occurred, different shapes of cylinder orbits were observed along the cylinder length, which indicated that the phase difference varied along the length.

However, most of these studies are primarily in subcritical-Reynolds-number region, and very few studies were done at supercritical-Reynolds-number between $3.2 \times 10^{5}$ and $7.1 \times 10^{5}$. Dahl et al. (2010) compared experimental results of VIV of a rigid cylinder in subcritical-Reynolds-number region and supercritical-Reynolds-number region. They concluded that except for slight differences in magnitudes of force and response, strong similarities in experimental results such as dual resonance were observed in the two Reynolds number regions.

\subsection{Higher harmonics in forces and responses}

In early experiments responses were primarily at low modes, in which higher harmonics in responses and forces were quite insignificant. In recent experiments (Baarholm et al., 2006; Trim et al., 2005; Vandiver et al., 2009), very high modes (over thirty) were excited by vortex shedding and the higher harmonics in responses were remarkable.

\subsubsection{Explanation for higher harmonics in forces}

The third harmonic in lift force was observed to be related to the shedding of three vortices in wake behind the cylinder, i.e. 2T mode in experiments (Dahl et al., 2007; Jauvtis and Williamson, 2004). Although energy at the fourth and the fifth harmonic frequencies was noticed in early experimental data, no explanation was provided for why and when they occurred, except that they might be necessary Fourier components of the fundamental periodic vortex-induced force. One possible explanation is given for the occurrence of the higher harmonic in force as the following.

When a cylinder oscillates as a result of vortex shedding, due to the relative motion of the cylinder, the lift and drag forces do not coincide with the $x$ and $y$ axes, respectively, as shown in Fig. 5(b). Fig. 5(a) is an illustration of fluid forces when the cylinder is stationary. The force coefficients applied on vibrating cylinder are thus expressed as

$$
\begin{aligned}
& c_{x}(t)=c_{\mathrm{D}}(t) \cos \theta-c_{\mathrm{L}} \sin \psi, \\
& c_{y}(t)=c_{\mathrm{D}}(t) \sin \theta+c_{\mathrm{L}} \cos \psi .
\end{aligned}
$$

In general, the angle $\psi$ is very small and Eq. (3) is simplified to (Wang et al., 2003)

$$
\begin{aligned}
& c_{x}(t)=c_{\mathrm{D}}(t)-c_{\mathrm{L}} \dot{Y}(t), \\
& c_{y}(t)=c_{\mathrm{D}}(t) \dot{Y}(t)+c_{\mathrm{L}}(t),
\end{aligned}
$$

where $\dot{Y}(t)$ is the cylinder velocity in CF direction.

For a cylinder having two degrees of freedom, the IL and CF displacements, and the definition of phase angles between force and displacement in CF and IL directions are shown in Fig. 6. The displacements and forces of cylinder undergoing VIV can be written as (Jauvtis and Williamson, 2004)

$$
\begin{aligned}
& y(t)=A_{Y} \sin (\omega t) \\
& x(t)=A_{X} \sin (2 \omega t+\theta), \\
& f_{\mathrm{L}}(t)=f_{\mathrm{L} 0} \sin \left(\omega t+\phi_{Y}\right) \\
& f_{\mathrm{D}}^{\prime}(t)=f_{\mathrm{D} 0}^{\prime} \sin \left[2 \omega t+\left(\phi_{X}+\theta\right)\right], \\
& F_{y}=f_{\mathrm{L}}(t)+\frac{\omega A_{Y} f_{\mathrm{D} 0}^{\prime}}{2}\left\{\sin \left[3 \omega t+\left(\phi_{x}+\theta\right)\right]+\sin \left[\omega t+\left(\phi_{x}+\theta\right)\right]\right\} .
\end{aligned}
$$

Substituting Eqs. (5) and (6) into Eq. (4), then according to Eq. (7), we notice that a third harmonic appears in the lift force expression. With Eq. (7) substituted into Eq. (4), the fourth harmonic is obtained in the drag force expression.
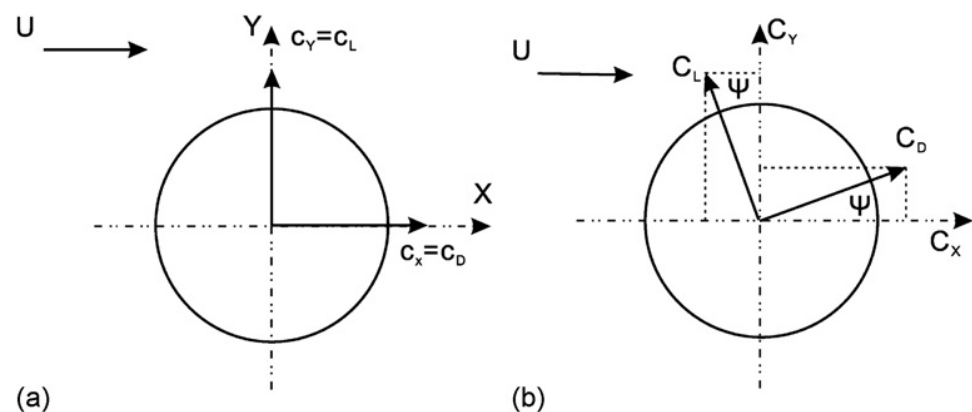

(b)

Fig. 5. Illustration of fluid force. (a) Still cylinder and (b) vibrating cylinder (Wang et al., 2003). 


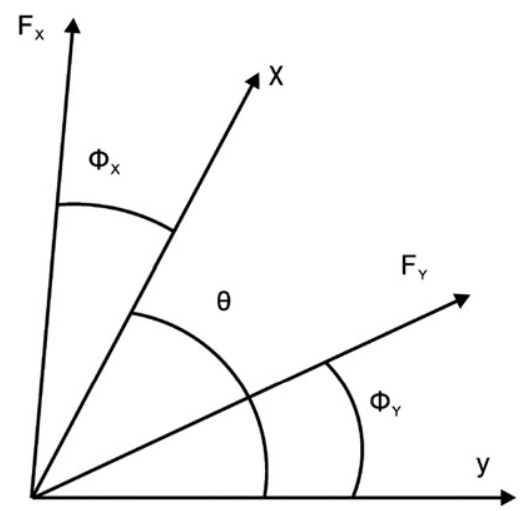

Fig. 6. Definition of phase angles between force and motion.
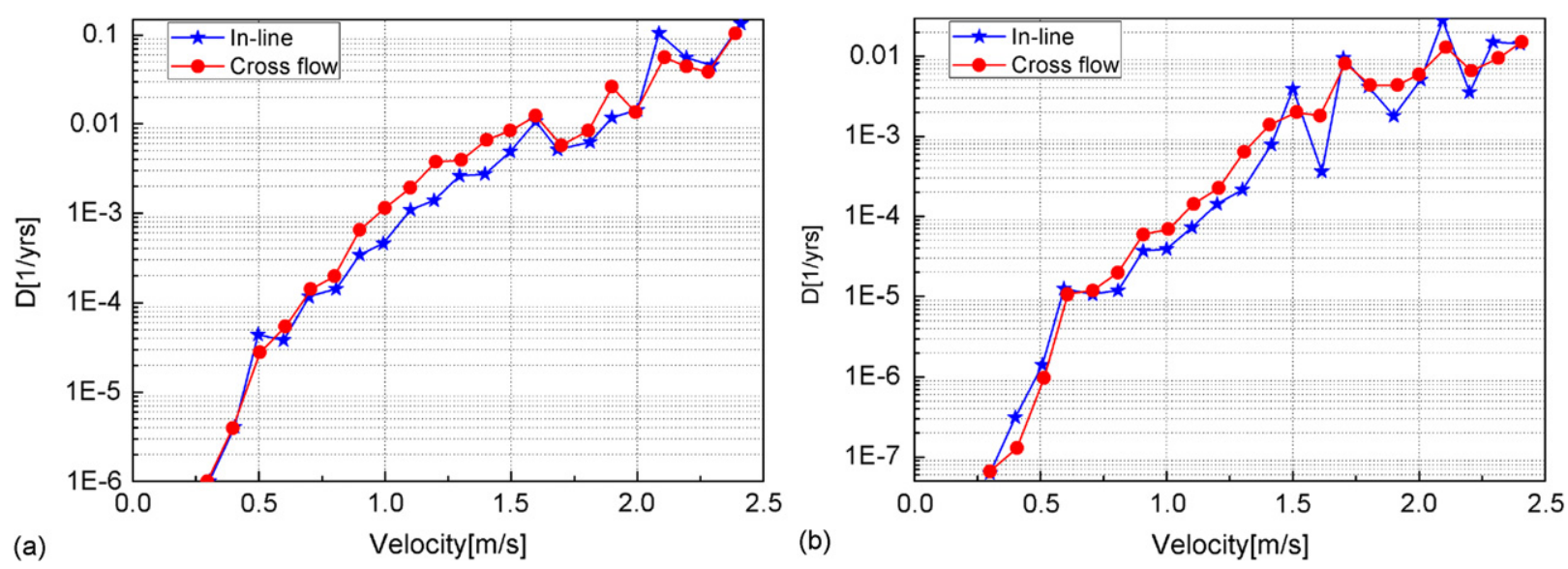

Fig. 7. CF and IL fatigue versus tow speed for bare riser. (a) Uniform flow and (b) sheared flow (Trim et al., 2005).

By substituting lift force and drag force expressions into Eq. (4) iteratively, the lift force will include odd harmonic components and the drag force will include even harmonic components.

The phase angle $\theta$ between IL and CF vibrations is a very important controlling parameter, which determines the higher harmonics in lift force. It is supposed that, when $\theta$ is in proper range, the higher harmonics are significant and in phase with the fundamental component, thus favoring the whole lift force. Dahl et al. (2007) gave the phase angles that favor lift force from $325^{\circ}$ to $90^{\circ}$.

\subsubsection{The second harmonic}

The results of early research showed that the second harmonic force was the in-line component of the hydrodynamic force that caused the vibrations at the fundamental VIV frequency. Nevertheless the IL response at twice the fundamental VIV frequency was considered less important than the CF response. This was primarily because the measured IL displacement amplitude was smaller than the displacement amplitude in CF direction. By the end of last century, it had become clear that the response in the IL direction, though not as large as CF direction, was significant for long slender cylinders. Trim et al. (2005) indicated that while IL displacement was less than CF displacement, the modal curvature and vibrating frequency, which dominated fatigue damage, were much larger. Fig. 7 shows the maximum fatigue damage along the riser as a function of the tow speed in uniform and sheared flow for IL and CF directions. It is apparent that IL fatigue damage is about the same as CF fatigue damage. Baarholm et al. (2006) observed that IL response had a significant contribution to fatigue when the response was dominated by the lower order modes, while CF response contributed more to fatigue if the higher order modes dominated the response.

The presence of IL vibration has a significant change on the flow pattern behind the cylinder and therefore may enhance CF vibration. In laboratory experiments using rigid cylinders, Jauvtis and Williamson (2004) observed that the amplitude of VIV displacement response in the CF direction increased significantly when IL vibration was allowed. When the mass ratio was reduced to the values corresponding to most ocean structures, they observed very large amplitudes of CF vibration. Vibrations with the largest amplitude were associated with a 'super upper' branch of motion, where the 
amplitudes were as large as $A_{y} / D=1.5$. They also noted that the significant third harmonic component of lift force occurred when the vibration was in the super upper branch.

\subsubsection{The third and higher harmonics}

The third harmonic response used to be ignored because its contribution to the whole displacement in the CF direction was very small. The third harmonic component in lift force was noticed by Jauvtis and Williamson (2004). They observed that the third harmonic component in lift force was associated with the 2T vortex shedding mode.

Jauvtis and Williamson (2004) also observed that the occurrence of strong third harmonic in lift force was related to certain motion trajectories, which are controlled by the phase angle between IL and CF vibrations. This is consistent with the conclusion drawn from Eq. (7). Then they showed the motion trajectories for different phase angles and presented that the motion trajectories for super upper branch were in crescent shape, with $\theta=270^{\circ}$. It was slightly different from the phase angle given later by Dahl et al. (2007). They explained that the existence of the third harmonic may be attributed to the interaction of the motion trajectory of cylinder and vortices in its wake. The flow visualization showed that at or near the phase angle of $0^{\circ}$, the cylinder downstream motion brought it close to the just shed vortices, thereby strengthening the lift force (Dahl et al., 2007).

Vandiver et al. (2009) observed the third harmonic response in their field tests. Fig. 8 indicates that in some locations of cylinder the third harmonic response exhibits very strong spectra. The contribution from the third harmonic to the whole strain response is even larger than that from the fundamental component of response, as shown in Fig. 9.

Although the fourth and the fifth harmonics were mentioned in early literature, these harmonics were observed extensively until the recent experiments of Vandiver et al. (2009). Fig. 8 shows that the fourth and fifth harmonics have notable peaks of spectra and in some locations the energy of the fourth harmonic is larger than those of the first and the second harmonics. Fig. 9 indicates that the contribution from the fourth and the fifth harmonics to the whole strain response is very remarkable.

The third and higher harmonics have substantial influence on the fatigue damage of long slender cylinders. Jhingran and Vandiver (2007) estimated the fatigue damage induced by these higher harmonics based on the experimental data of Jaiswal and Vandiver (2007). They suggested that the contribution from the higher harmonics was quite considerable, in some cases, even larger than that from the fundamental harmonic. By analyzing the experimental data from the Norwegian Deepwater Program (NDP) VIV tests (Trim et al., 2005), Mukundan et al. (2009) and Modarres-Sadeghi et al. (2010) also noted the effect of the third harmonic on fatigue life of the experimental model, and presented a fatigue estimation method, which took into account the influence of the higher harmonics.
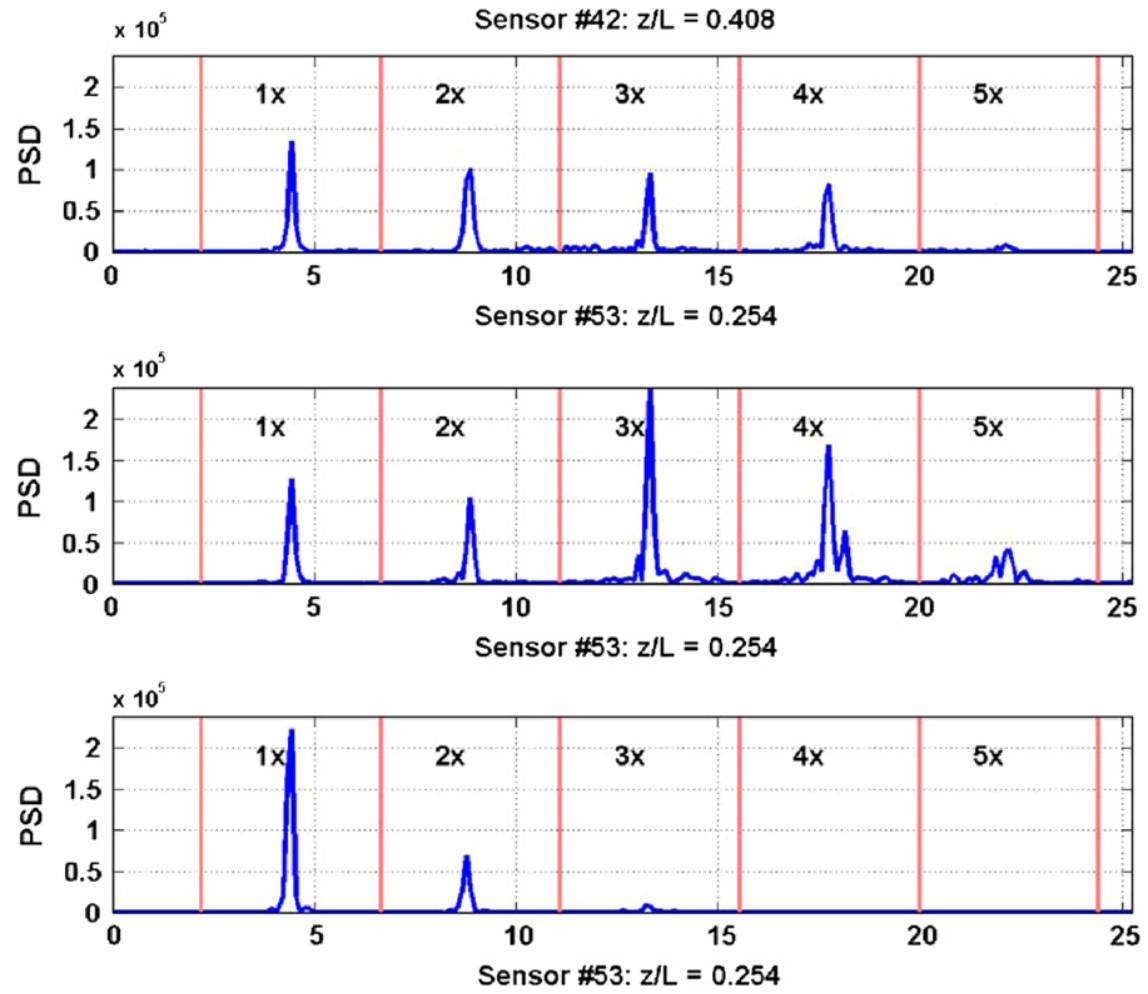

Fig. 8. Spectra at three different locations (Vandiver et al., 2009). 

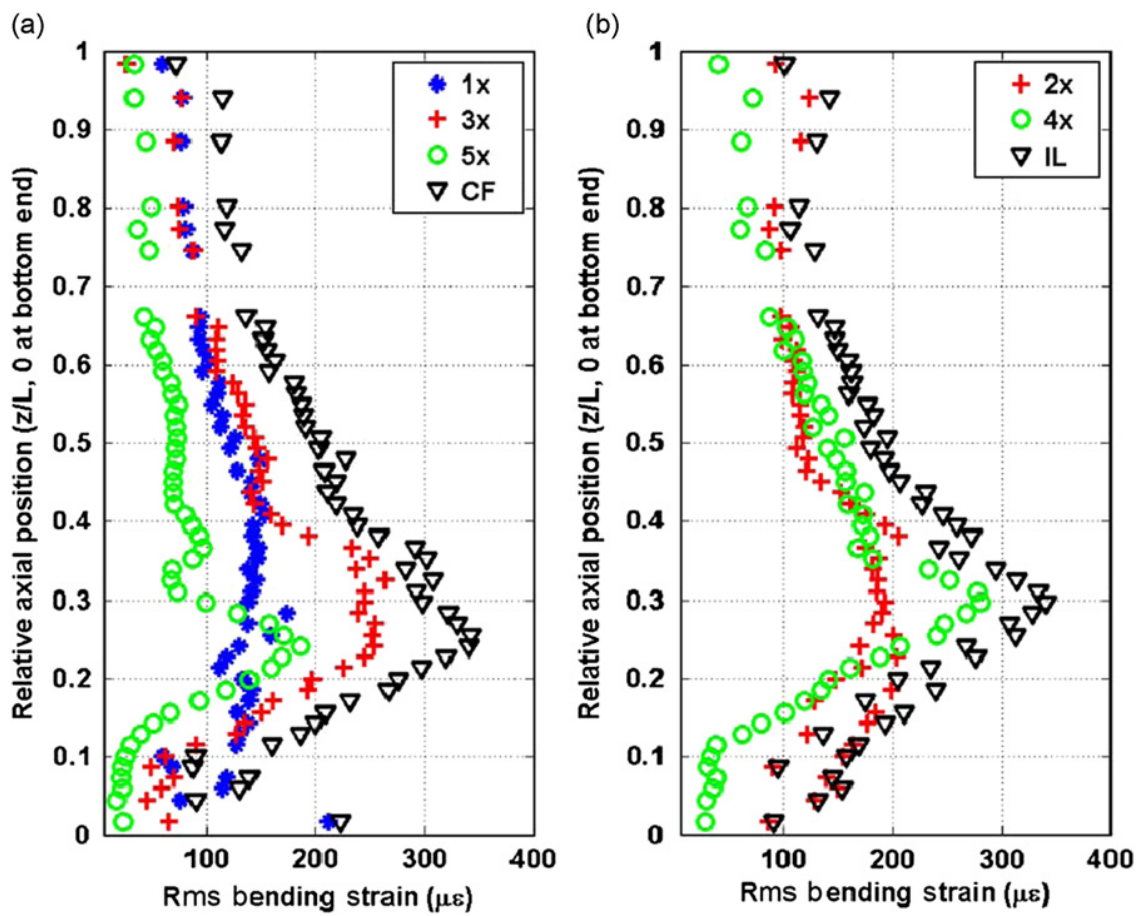

Fig. 9. Strain components. (a) Cross-flow (odd harmonics) and (b) in-line (even harmonics) (Vandiver et al., 2009).

\subsubsection{Displacement versus strain or acceleration}

The displacement response amplitude is usually taken as an indicator of structure failure. Since the transfer function from force to displacement filters out the third and higher harmonic forces (Jauvtis and Williamson, 2004), the displacement response is only dominated by the first and the second harmonics and does not contain the contribution from higher harmonics in force. However the contribution from higher harmonic forces to strain or acceleration response is quite remarkable for long slender cylinders (Jhingran, 2008). Therefore it is believed that strain or acceleration response is a more reliable indicator of the likelihood of structure failure.

\subsection{Traveling wave dominated response pattern}

\subsubsection{Traveling wave vibrations}

According to Vandiver (1993b), the wave propagation parameter $n \xi_{n}$ was used to predict the type of response to be expected, where $\xi$ is the hydrodynamic source of damping and $n$ is the mode number. They suggested that if this parameter is less than 0.2 , the response is in clear standing wave behavior. If it is larger than 2.0 , infinite cable behavior is the dominant feature. Between 0.2 and 2.0, the response of cylinder is the combination of both and the spatial attenuation along the length is obvious. By means of dimensional analysis, similar controlling parameters, which determine the wave types of vibration were obtained by Zhang et al. (2010).

According to the established knowledge, for slender structure vibrating in combination of traveling wave and standing wave, a large standing wave region forms near the bottom end boundary and its amplitude increases as approaching the bottom end. The peak strain and fatigue damage rates are expected to locate at the antinodes of standing wave. However, this is not the case in the experiments of Vandiver et al. (2009). They observed that the measured total peak RMS CF strain did not locate near the ends of the model, where the response was in standing wave. It located in the traveling wave region, as indicated in Fig. 10. The energy in the standing wave region was weak, while in traveling wave region was very strong, as shown in Fig. 11.

$\mathrm{Ge}$ et al. (2009) presented the calculated displacement response in different wave types, in a certain range of flow velocities. As shown in Fig. 12, when the towing speed is equal to $1.5 \mathrm{~m} / \mathrm{s}$, standing wave dominates almost all over the riser in CF direction. As the towing speed increases, traveling wave occurs and progressively dominates the response away from the riser ends. The higher the towing speed the cylinder is subjected to, the higher order the modes excited, and according to the foregoing criterion, the more likely the occurrence of traveling wave dominance. The IL force is at twice the frequency of CF force, thus the cylinder responds at higher order mode in IL direction and the dominance of traveling wave appears earlier in IL direction than in CF direction with the increase of towing speed. As shown in Fig. 13, when the towing speed is equal to $1.5 \mathrm{~m} / \mathrm{s}$, the traveling wave begins to appear in IL direction and with the increase of towing speed the traveling wave quickly dominates almost the whole cylinder. 


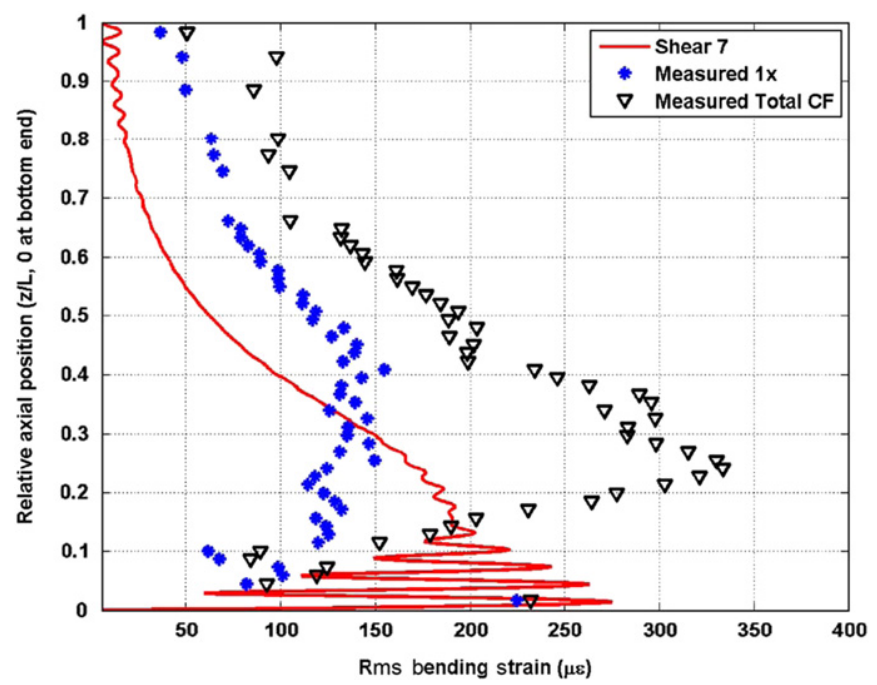

Fig. 10. Shear7 predicted strain response, measured first harmonic of strain and measured total cross-flow strain (Vandiver et al., 2009).

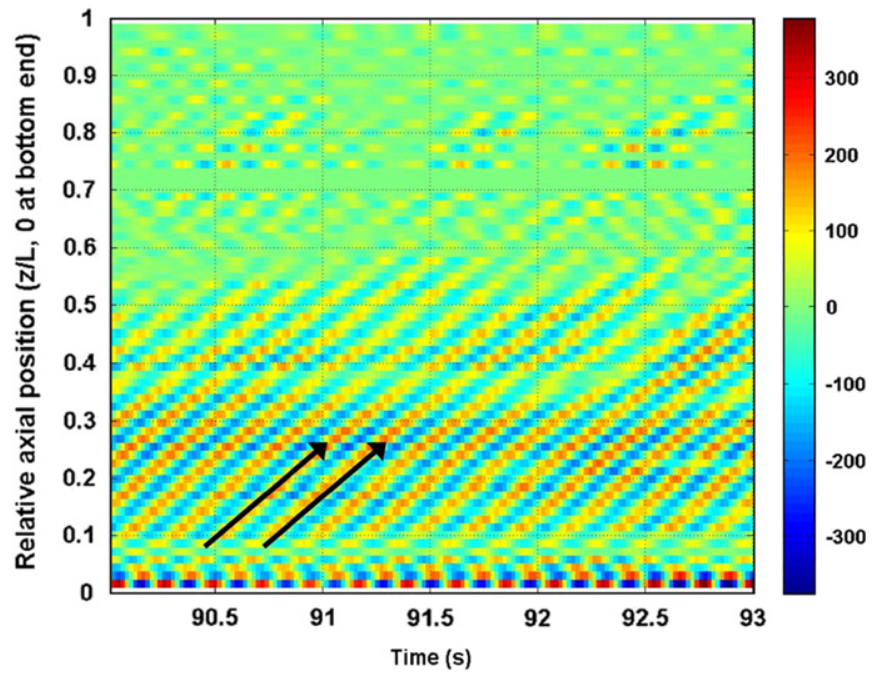

Fig. 11. Strain time series at all sensor locations showing traveling wave propagating with speed approximately $40 \mathrm{~m} / \mathrm{s}$ (Vandiver et al., 2009).

Newman and Karniadakis (1997) showed that when the traveling wave dominates the response, the vortex trails are shed obliquely in the flow and not perpendicular to the axis of the cylinder, as seen in Fig. 14(a). The lift force due to the oblique vortex shedding, which is phase-locked to the traveling wave, maintains the traveling wave pattern. They suggested that the interaction between them will make the traveling wave dominated pattern to be a very stable phenomenon. In contrast, Fig. 14(b) shows that, in the standing wave dominated case, the two sheets of spanwise vortices form an interwoven pattern.

\subsubsection{Wave dispersion}

In the case of time-harmonic waves, the dispersion of wave leads to phase velocity varying with the wavelength or frequency. Since the IL response is at the distinct frequency from that observed in CF response, we propose that, due to the wave dispersion the IL phase velocity may be different from that in CF direction; therefore, phase angle between IL and CF vibrations may change along the length of cylinder.

Vandiver et al. (2009) proposed that a difference in added mass as well as bending stiffness would lead to phase velocity difference. One possible explanation is given that the tension dominated cylinder and the bending stiffness dominated cylinder are in identical sine modal shapes with the same wavelengths as $2 L / n$. By considering the natural frequencies from Eqs. (1) and (2), the phase velocities are derived, respectively, as

$$
c=\sqrt{\frac{T}{m}},
$$




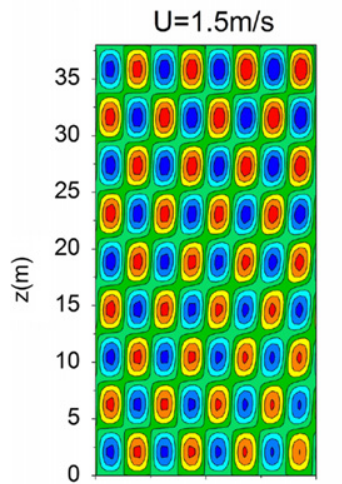

$U=2.0 \mathrm{~m} / \mathrm{s}$

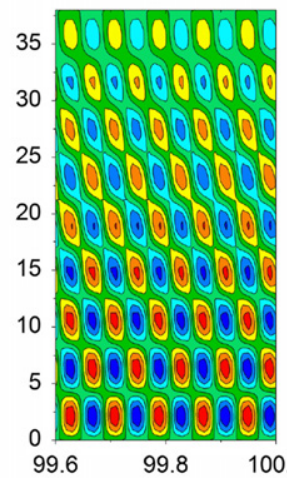

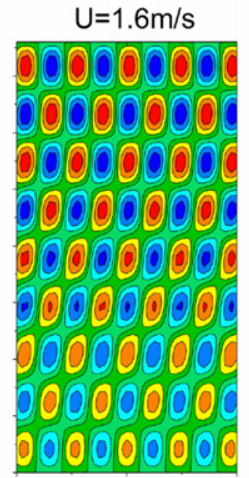

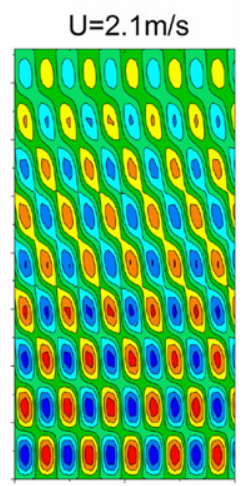

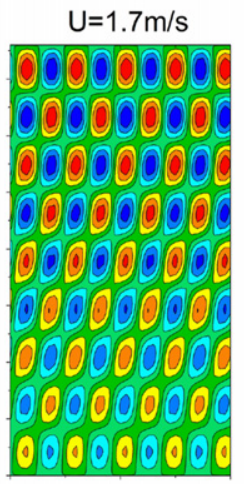

$\mathrm{U}=2.2 \mathrm{~m} / \mathrm{s}$

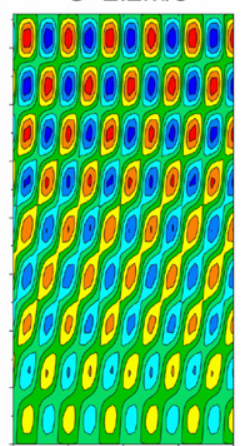

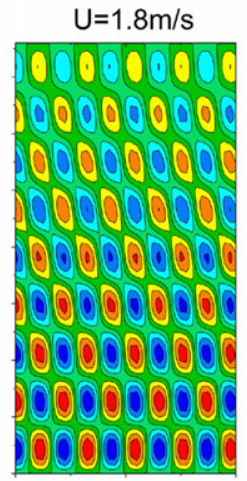

$\mathrm{U}=2.3 \mathrm{~m} / \mathrm{s}$

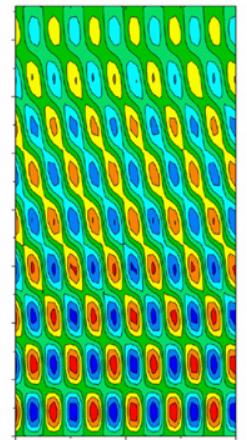

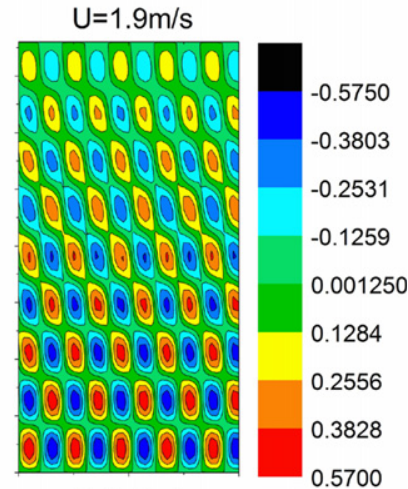

$\mathrm{U}=2.4 \mathrm{~m} / \mathrm{s}$

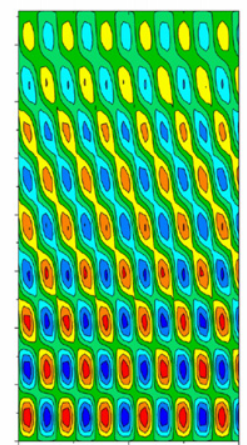

Time(s)

Fig. 12. Time series of CF displacements (Ge et al., 2009).

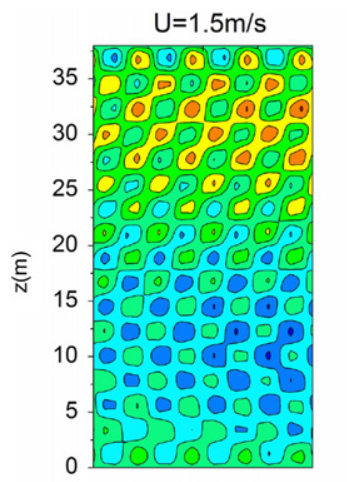

$\mathrm{U}=2.0 \mathrm{~m} / \mathrm{s}$

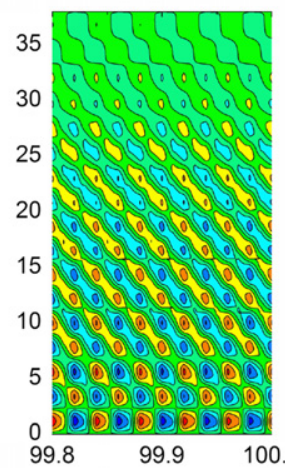

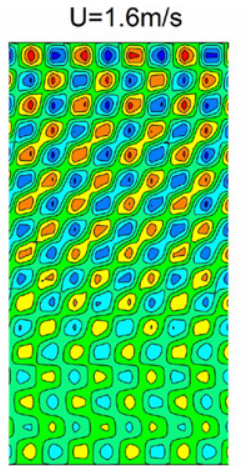

$\mathrm{U}=2.1 \mathrm{~m} / \mathrm{s}$

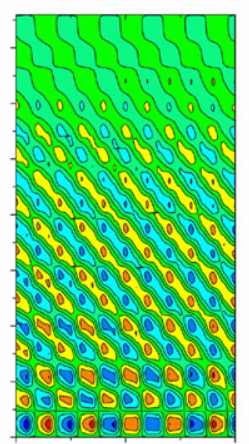

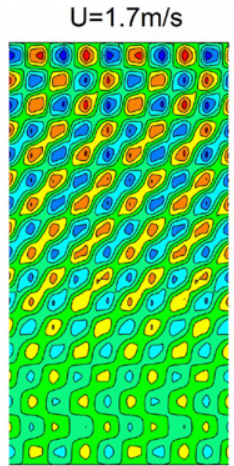

$\mathrm{U}=2.2 \mathrm{~m} / \mathrm{s}$

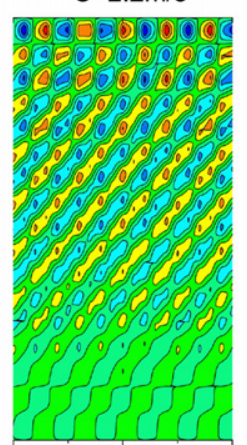

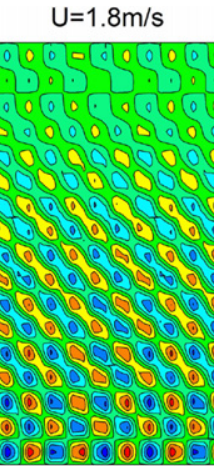

$\mathrm{U}=2.3 \mathrm{~m} / \mathrm{s}$

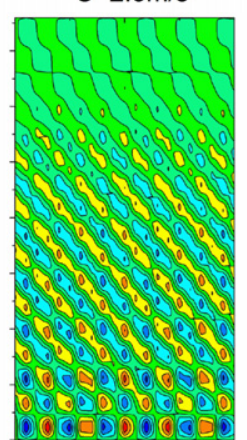

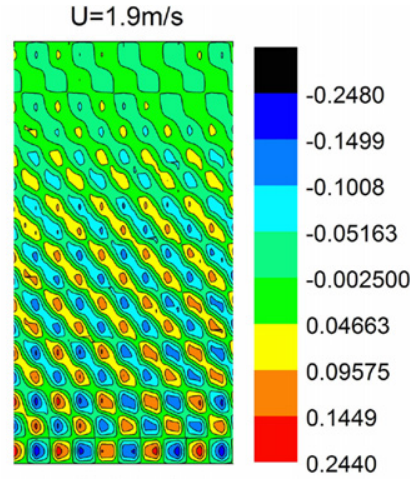

$\mathrm{U}=2.4 \mathrm{~m} / \mathrm{s}$

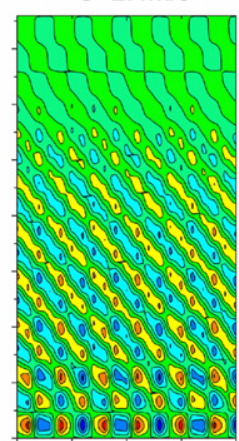

Time(s)

Fig. 13. Time series of IL displacements (Ge et al., 2009). 


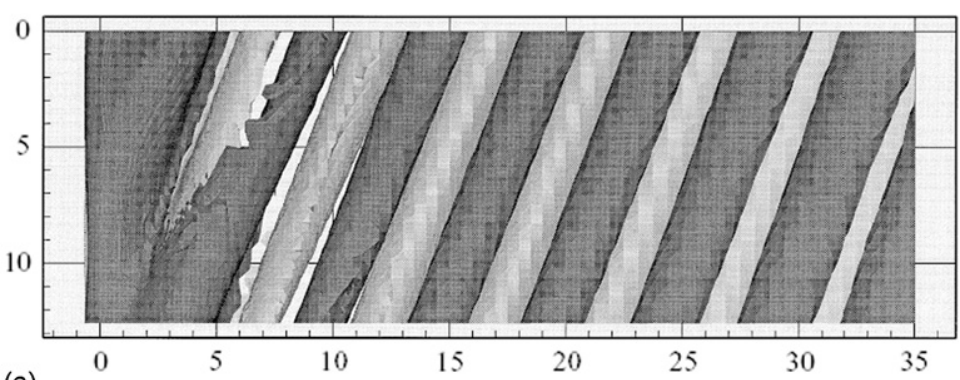

(a)

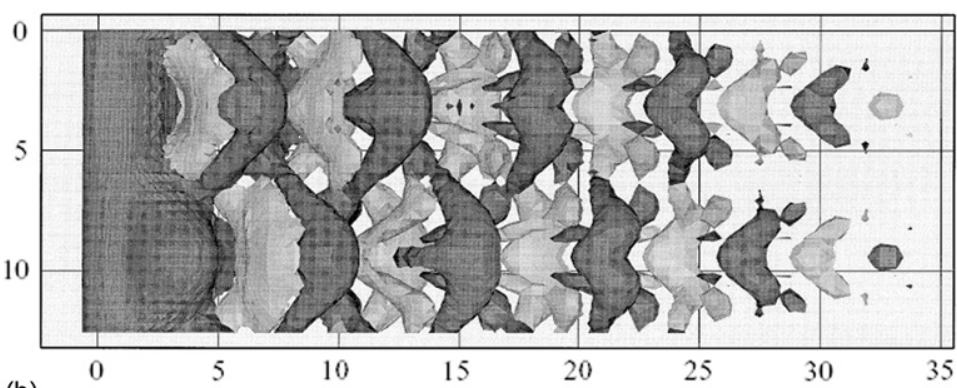

(b)

Fig. 14. Top views of spanwise vortices for the traveling wave cable response (a) and the standing wave cable response (b) (Newman and Karniadakis, 1997).

$$
c=\frac{n \pi}{L} \sqrt{\frac{E I}{m}}
$$

The phase propagation of the wave reacts as a combination of the both. According to Eq. (8), for the tension dominated cylinder, the phase velocity difference in CF and IL directions is probably induced by the added mass difference between the two directions. As for the actual riser with elastic base, according to Eq. (9), the authors believed the IL vibration is at the distinct mode from that of CF vibration, which could lead to phase velocity difference in two directions. Besides, for some structures such as steel catenary riser, the differences of bending stiffness between IL and CF directions may also lead to the wave dispersion.

For long slender cylinders, phase velocity differences result in the considerable variation of phase angle along the length of the cylinder (Vandiver et al., 2009). Fig. 15 shows that the motion trajectories exhibit significant variation along the length of cylinder, where the phase angle controls the motion trajectories (Fig. 16). For short rigid cylinder, due to the small traveling distance, the phase angle almost keeps constant along the length. Dahl et al. (2010) reported a constant phase angle along the length of a short rigid cylinder. In the experiment by Huera-Huarte and Bearman (2009), the variation of phase angle along the length of the experimental model is not evident either.

As mentioned in Section 2.2.3, the phase angle has significant influence on the third harmonic force. Vandiver et al. (2009) suggested that on long slender cylinder traveling wave permitted the ideal phase angles between IL and CF vibrations, which favored the large third harmonic lift force.

\section{Methods for predicting VIV of long slender cylinders}

The long slender cylinder often suffers the high Reynolds number in ocean environment, and its dynamic characters and vortex shedding modes vary along its length. Thus the prediction of VIV of such structure is much more complicated. Chaplin et al. (2005b) compared 11 different methods for predicting VIV of a long tensioned riser. They found that the CF displacements and curvatures computed by these different methods approached the measured data very well, whereas the IL response could not be predicted well by any of them.

According to the ways of acquiring fluid forces that applied on the oscillating structure, the methods for predicting VIV are divided into two categories, i.e. semi-empirical methods and computational fluid dynamics (CFD).

\subsection{Semi-empirical methods}

\subsubsection{Wake oscillator models}

Wake oscillator models have been proposed in many papers (e.g., Iwan, 1981; Landl, 1975; Skop and Balasubramanian, 1997; Skop and Griffin, 1973). The main difference between this approach and CFD is that the dynamic behavior of the fluid in the cylinder wake is modeled rather than being computed. These models usually do not include any analysis of the flow field and their parameter values are deduced based on experimental results. For this reason, these models are often referred to as phenomenological models. 


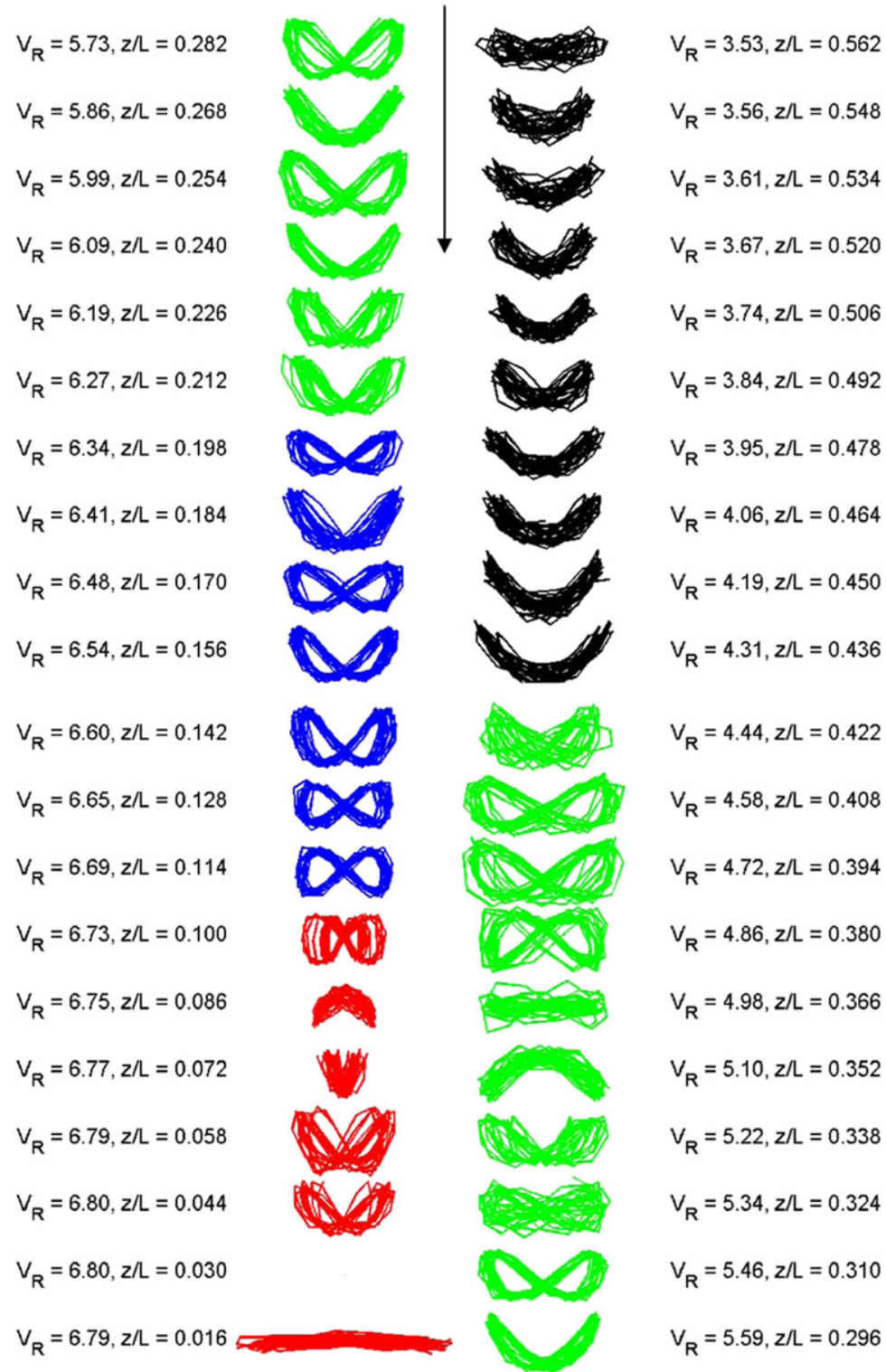

Fig. 15. Measured motion trajectories for the Miamill pipe from $z / L=0.016$ to $z / L=0.562$ (Vandiver et al., 2009).

Typical wake oscillators are based on nonlinear equations such as van der Pol equations. These oscillators have selfexciting and self-limiting characteristics, which make them capable of capturing such fundamental VIV phenomena as the self-limiting amplitude and lock-in. The natural frequency of the oscillator equals to the vortex shedding frequency so that the resonance between the oscillator and the cylinder takes place as the vortex shedding frequency comes close to one of the natural frequencies of the cylinder. The interaction between the cylinder motion and fluid is achieved by means of coupling between the structure equation and the wake oscillator. As for the coupling term, Facchinetti et al. (2004a) suggested that the most suitable forcing term is proportional to the acceleration of the cylinder. Nevertheless, some assumptions should be kept in mind when using the wake oscillator model, for example, the flow around the cylinder is nominal two-dimensional (2-D) (Gabbai and Benaroya, 2005), the vortex shedding along the cylinder is at full correlation length when lock-in occurs and the effect of boundaries on the flow is neglected. Being phenomenological, these models are at best able to explain and simulate experimental results (Gabbai and Benaroya, 2005). Since underlying physical mechanisms are not clearly known, some new phenomena such as the third harmonic forces have not yet been taken into account in the simulation given by wake oscillator models.

When traditional wake oscillator models are used for predicting VIV of long slender cylinders, the three-dimensional (3-D) features should be considered. In 3-D model, wake oscillators are continuously distributed along the length of 


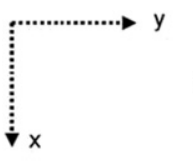

90
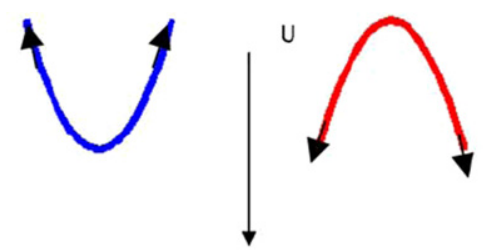

270 45
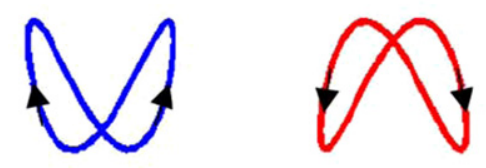

225

0
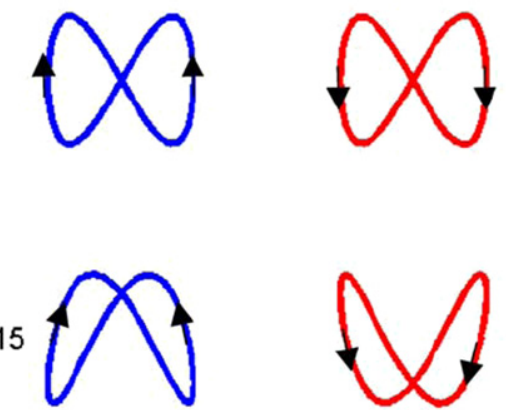

180

135

Fig. 16. Relationship between IL and CF motion phase angle and trajectories (Vandiver et al., 2009).

cylinder and allowed to interact directly (Balasubramanian and Skop, 1996; Chen et al., 2010; Facchinetti et al., 2004a; Kim and Perkins, 2002). Facchinetti et al. (2004b) predicted the response of VIV and VIW (vortex induced waves) for cables with such a 3-D wake oscillator model. Mathelin and de Langre (2005) simulated the response of VIV and VIW under a sheared flow. They found that the response of a tensioned cable under sheared flow presented wave-packets distributed along its length. Violette et al. (2007) also developed a 3-D wake oscillator model, which is based on the model proposed by Facchinetti et al. (2004a). They employed the term $\omega_{f}=U(z) / U_{\text {ref }}$ to represent the variation of flow velocity along the length of the cylinder, where $\omega_{f}$ is the normalized shedding frequency, $U(z)$ and $U_{r e f}$ are the flow velocities at spanwise location $z$ and the reference flow velocity, respectively. With this model, they simulated three cases including a long slender structure case. Fig. 17(b) shows that, in the case of long structure, traveling wave dominates the vibration regime, which fits the CFD results of Fig. 17(a) very well. Recently by considering the linear stability of the model of Facchinetti et al. (2004a), Violette et al. (2010) interpreted several phenomena observed in the experiments of VIV of long slender cylinders, such as range of unstable wave numbers, mode transition or mode switching with flow velocity, time sharing and space sharing. Farshidianfar and Zanganeh (2010) presented a modified wake oscillator model, which captured the dynamic features of the model over a wide range of mass-damping ratios. Based on the model of Skop and Balasubramanian (1997), Srinil (2010) proposed a low-order model capable of simulating the multi-mode interactions of flexible curved or straight structures.

Wake oscillators that take both the CF and IL vibrations into account are quite few. The IL VIV may occur in the same range of reduced velocity as that of CF VIV. Moreover, IL VIV has a vortex shedding frequency twice that of CF VIV. Therefore, the natural frequency of IL oscillator model is twice that of CF oscillator model. Kim and Perkins (2002) expanded the model of Skop and Balasubramanian (1997) to the CF/IL case. In their modified model, coupling between CF and IL vibrations are evaluated by considering structural nonlinearities and coupling between fluid lift and drag forces. Ge et al. (2009) presented a non-linear wake oscillator considering both the CF and IL vibrations. Their simulations obtained some important dynamic features of long slender cylinders. Following the work of Ge et al. (2009), Wu et al. (2010) discussed the effect of traveling wave on VIV of SFT tethers.

\subsubsection{Predicting VIV using data measured in forced vibrations}

For long slender circular cylinders, it is a simple and fast way to predict the responses of VIV with the help of measured data. Several codes were established for the prediction by this method, such as VIVA (Triantafyllou, 2003) and SHEAR7 (Vandiver, 1999). As Chaplin et al. (2005b) mentioned, these codes could make good prediction on CF vibration. The predicted results were between $85 \%$ and $105 \%$ of the corresponding measurements.

Many of these methods are based on an assumption that the flow around a cylinder undergoing free or forced oscillation is identical. Morse and Williamson $(2006,2009)$ suggested that controlled vibration could reasonably predict 
(a)

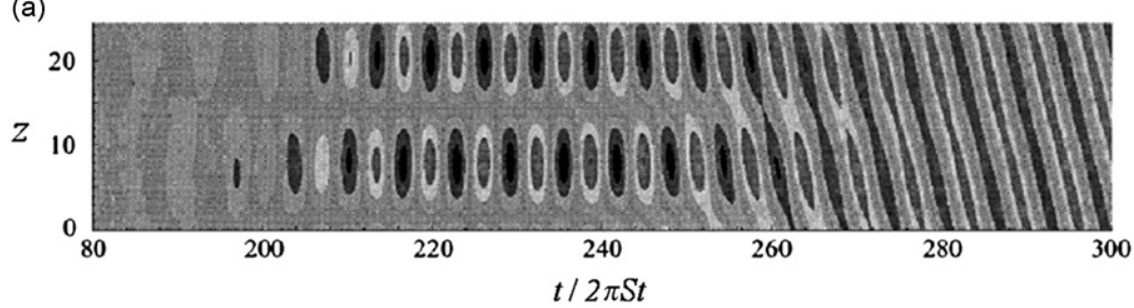

(b)

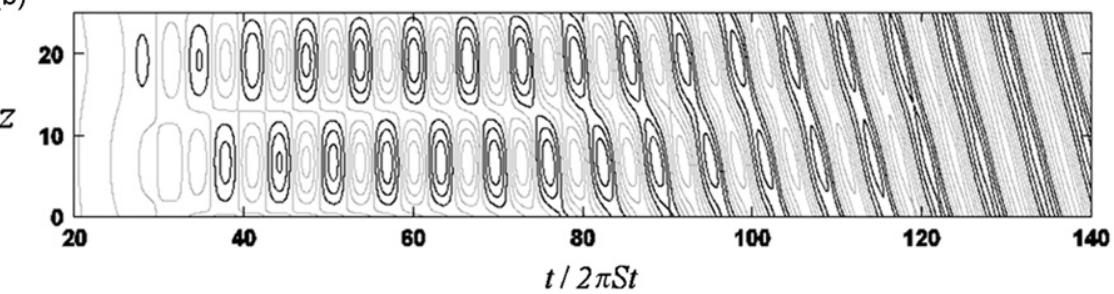

Fig. 17. Evolution of cable displacement with time and space: (a) DNS and (b) wake oscillator (Violette et al., 2007).

free vibration responses, at least over the parameter space $\left(A^{*}, \lambda^{*}\right)$, where the amplitude $A^{*}$ and the wavelength $\lambda^{*}$ are normalized by the cylinder diameter.

Bearman (2009) commented on the study of Morse and Williamson (2006, 2009), arguing that only CF motion was allowed and considering only one mode. However, a long slender cylinder such as a cable possesses many modes of vibration and may vibrate in both IL and CF directions. In this case, two amplitudes and two wavelengths, as well as a phase angle between the motions should be considered.

Dahl et al. (2008) successfully predicted free vibration steady-state oscillations in both IL and CF directions using the forced oscillation data. Their forced oscillation data were acquired by performing forced motions of a rigid cylinder in both IL and CF directions. They predicted successfully the dominant large amplitude of the third harmonic force in the lift force.

\subsection{Response prediction using CFD}

CFD simulations are regarded as an ideal method for predicting the VIV of long slender cylinders. However such simulations are still very few, due to the fact that extensive computational requirements limit the 3-D CFD simulation at realistic Reynolds numbers.

Al-Jamal and Dalton $(2004,2005)$ compared the difference between 2-D and 3-D CFD simulations. They concluded that 2-D simulation did a reasonably good estimation for global parameters such as drag and lift coefficients, especially when VIV occurred. The disadvantage of 2-D simulation is that the influence of the spanwise wake turbulence is omitted. Pontaza and Chen (2007) and Pontaza et al. (2009) presented 3-D LES (large eddy simulation) results for an isolated cylinder undergoing two degrees of freedom vibrations. Their simulation showed that VIV at the supercritical Reynolds number of $10^{6}$ is of small magnitude under smooth surface condition, but of significant amplitude under rough surface condition. Yamamoto et al. (2004) simulated VIV of a long cylinder with DVM (discrete vortices method); their results, such as the variation of the amplitude with reduced velocity, fitted the experiments very well.

When the cylinder was allowed to vibrate in both IL and CF directions, Lucor and Triantafyllou (2008) noticed an increase of the CF response amplitude compared to the case without IL motion. They also found that the lift forces that attributed to the $\mathrm{CF}$ maximum response had a significant 3rd harmonic frequency component.

\section{Concluding remarks}

VIV is an inherently non-linear, self-regulated motion with multi-degrees of freedom. For long slender cylinders, the patterns of vibrating behavior excited by vortex shedding are significantly different from those of short rigid cylinders. The response under lock-in is no longer in single mode, and presents a multi-mode behavior. The lock-in for such cylinders can be defined as that single mode dominates the response, whereas other modes are suppressed. Higher harmonics in forces and responses, though ignored in the past, were very notable in recent experiments. The wave propagation along the length of long slender cylinders has striking features, the traveling wave dominates the whole response, and owing to the wave dispersion, the phase angle between IL and CF motions exhibits large variation along the length of the cylinder. Although the selected papers highlight these behaviors both in experiments and numerical simulations, their effects on the VIV of long slender cylinders need to be further studied. For short rigid cylinders, the IL vibration, the higher harmonic lift force and the variation of flow velocity along the cylinder length have little effect on VIV. Nevertheless, as the aspect ratio increases to the order of $10^{2}-10^{3}$, these factors have strong influence on the VIV. 
A series of model tests for VIV of long slender cylinders have been performed. These tests were conducted in ocean environment or large-scale water tanks, and equipped with very large facility and relatively complicated instrumentation. This restricts extensive implementation of such tests. With the development of experiment and measurement techniques, model tests of cylinders with very large aspect ratio (over $10^{3}$ ) are likely to achieve in relatively small-scale water tanks. This will surely facilitate such tests to be conducted widely in the future.

With the development of computer capacity and employment of parallel computation, flow-field simulation for VIV of long slender cylinders could be carried out at high Reynolds number. This may lessen the gap between the numerical simulation and practical application in the Reynolds range or other flow conditions. Moreover, semi-empirical methods such as wake oscillator models, for given appropriate values of parameters, are available for a fast prediction with acceptable accuracy.

\section{Acknowledgments}

This paper is supported by the Knowledge Innovation Program of Chinese Academy of Sciences (Grant no. KJCX2-YW-L07).

\section{References}

Al Jamal, H., Dalton, C., 2004. Vortex induced vibrations using large eddy simulation at a moderate Reynolds number. Journal of Fluids and Structures $19,73-92$.

Al Jamal, H., Dalton, C., 2005. The contrast in phase angles between forced and self-excited oscillations of a circular cylinder. Journal of Fluids and Structures 20, 467-482.

Alexander, C.M., 1981. The complex vibrations and implied drag of a long oceanographic wire in cross-flow. Ocean Engineering 8, 379-406.

Baarholm, G.S., Larsen, C.M., Lie, H., 2006. On fatigue damage accumulation from in-line and cross-flow vortex-induced vibrations on risers. Journal of Fluids and Structures 22, 109-127.

Balasubramanian, S., Skop, R.A., 1996. A nonlinear oscillator model for vortex shedding from cylinders and cones in uniform and shear flows. Journal of Fluids and Structures 10, 197-214.

Bearman, P.W., 2009. Understanding and predicting vortex-induced vibrations. Journal of Fluid Mechanics 634, 1-4.

Bearman, P.W., 2011. Circular cylinder wakes and vortex-induced vibrations. Journal of Fluid Mechanics 27, 648-658.

Blackburn, H.M., Henderson, R.D., 1996. Lock-in behavior in simulated vortex-induced vibration. Experimental Thermal and Fluid Science 12, 184-189.

Blackburn, H.M., Govardhan, R.N., Williamson, C.H.K., 2001. A complementary numerical and physical investigation of vortex-induced vibration. Journal of Fluids and Structures 15, 481-488.

Blevins, R.D., Coughran, C.S., 2009. Experimental investigation of vortex-induced vibration in one and two dimensions with variable mass, damping, and Reynolds number. Journal of Fluids Engineering 131, 101202.

Bourguet, R., Karniadakis, G.E., Triantafyllou, M.S., 2011. Lock-in of the vortex-induced vibrations of a long tensioned beam in shear flow. Journal of Fluids and Structures 27, 838-847.

Brika, D., Laneville, A., 1993. Vortex-induced vibrations of a long flexible circular-cylinder. Journal of Fluid Mechanics 250, 481-508.

Chaplin, J.R., Bearman, P.W., Huera-Huarte, F.J., Pattenden, R.J., 2005a. Laboratory measurements of vortex-induced vibrations of a vertical tension riser in a stepped current. Journal of Fluids and Structures 21, 3-24.

Chaplin, J.R., Bearman, P.W., Cheng, Y., Fontaine, E., Graham, J.M.R., Herfjord, M., Isherwood, M., Lambrakos, K., Larsen, C.M., Meneghini, J.R., Moe, G., Triantafyllou, M.S., Willden, R.H.J., 2005b. Blind predictions of laboratory measurements of vortex-induced vibrations of a tension riser. Journal of Fluids and Structures 21, 25-40.

Chen, W., Zheng, Z., Li, M., 2010 Multi-mode vortex-induced vibration of slender cable experiencing shear flow. In: Proceedings of first International Symposium on Archimedes Bridge, vol. 4, pp. 145-152.

Dahl, J.M., Hover, F.S., Triantafyllou, M.S., 2006. Two-degree-of-freedom vortex-induced vibrations using a force assisted apparatus. Journal of Fluids and Structures 22, 807-818.

Dahl, J.M., Hover, F.S., Triantafyllou, M.S., 2007. Resonant vibrations of bluff bodies cause multivortex shedding and high frequency forces. Physical Review Letters 99, 144503.

Dahl, J.M., Hover, F.S., Triantafyllou, M.S., 2008. High harmonic forces and predicted vibrations from forced in-line and cross-flow cylinder motions. In: International Offshore and Polar Engineering Conference Proceedings 2008, pp. 481-488.

Dahl, J.M., Hover, F.S., Triantafyllou, M.S., 2010. Dual resonance in vortex-induced vibrations at subcritical and supercritical Reynolds numbers. Journal of Fluid Mechanics 643, 395-424.

de Langre, E., 2006. Frequency lock-in is caused by coupled-mode flutter. Journal of Fluids and Structures 22, 783-791.

Facchinetti, M.L., de Langre, E., Biolley, F., 2004a. Coupling of structure and wake oscillators in vortex-induced vibrations. Journal of Fluids and Structures $19,123-140$.

Facchinetti, M.L., de Langre, E., Biolley, F., 2004b. Vortex-induced travelling waves along a cable. European Journal of Mechanics B-Fluids 23, 199-208.

Farshidianfar, A., Zanganeh, H., 2010. A modified wake oscillator model for vortex-induced vibration of circular cylinders for a wide range of massdamping ratio. Journal of Fluids and Structures 26, 430-441.

Feng, C.C., 1968. The Measurement of Vortex Induced Effects in Flow Past Stationary and Oscillating Circular and d-Section Cylinders. Master's Thesis, Department of Mechanical Engineering, the University of British Columbia, Canada.

Gabbai, R.D., Benaroya, H., 2005. An overview of modeling and experiments of vortex-induced vibration of circular cylinders. Journal of Sound and Vibration 282, 575-616.

Ge, F., Hui, L., Hong, Y.S., 2008. Nonlinear response of submerged floating tunnel to wave forces. Chinese Journal of Applied Mechanics 25, $207-211$.

Ge, F., Long, X., Wang, L., Hong, Y.S., 2009. Flow-induced vibrations of long circular cylinders modeled by coupled nonlinear oscillators. Science in China, Series G: Physics, Mechanics and Astronomy 52, 1086-1093.

Griffin, O.M., Ramberg, S.E., 1982. Some recent studies of vortex shedding with application to marine tubulars and risers. Journal of Energy Resources Technology 104, 2-13.

Huera-Huarte, F.J., Bearman, P.W., 2009. Wake structures and vortex-induced vibrations of along flexible cylinder-Part 1: Dynamic response. Journal of Fluids and Structures 25, 969-990.

Huera-Huarte, F.J., Bearman, P.W., 2011. Vortex and wake-induced vibrations of a tandem arrangement of two flexible circular cylinders with near wake interference. Journal of Fluids and Structures 27, 193-211.

Huera-Huarte, F.J., Gharib, M., 2011a. Flow-induced vibrations of a side-by-side arrangement of two flexible circular cylinders. Journal of Fluids and Structures 27, 354-366. 
Huera-Huarte, F.J., Gharib, M., 2011b. Vortex- and wake-induced vibrations of a tandem arrangement of two flexible circular cylinders with far wake interference. Journal of Fluids and Structures 27, 824-828.

Iwan, W.D., 1981. The vortex-induced oscillation of non-uniform structural systems. Journal of Sound and Vibration 79, $291-301$.

Iwan, W.D., Jones, N.P., 1987. On the vortex-induced oscillation of long structural elements. Journal of Energy Resources Technology $109,161-167$.

Jaiswal, V., Vandiver, J.K., 2007. VIV Response prediction for long risers with variable damping. In: ASME Conference Proceedings 2007, pp. 901-909.

Jauvtis, N., Williamson, C.H.K., 2004. The effect of two degrees of freedom on vortex-induced vibration at low mass and damping. Journal of Fluid Mechanics 509, 23-62.

Jeon, D., Gharib, M., 2001. On circular cylinders undergoing two-degree-of-freedom forced motions. Journal of Fluids and Structures 15 , 533-541.

Jhingran, V., Vandiver, J.K., 2007. Incorporating the higher harmonics in VIV fatigue predictions. In: ASME Conference Proceedings 2007, pp. 891-899.

Jhingran, V., 2008. Dragamplification and Fatigue Damage in Vortex Induced Vibration. Doctor of Philosophy Dissertation in Ocean Engineering, Prof. J.K. Vandiver, Supervisor, Department of Mechanical Engineering, Massachusetts Institute of Technology, Cambridge, MA, USA.

Khalak, A., Williamson, C.H.K., 1999. Motions, forces and mode transitions in vortex-induced vibrations at low mass-damping. Journal of Fluids and Structures $13,813-851$.

Kim, W.J., Perkins, N.C., 2002. Two-dimensional vortex-induced vibration of cable suspensions. Journal of Fluids and Structures $16,229-245$.

Kim, Y.H., Vandiver, J.K., Hollar, R., 1986. Vortex-induced vibration and drag coefficients of long cables subjected to sheared flows. Journal of Energy Resources Technology 108, 77-83.

Landl, R., 1975. A mathematical model for vortex-excited vibrations of bluff bodies. Journal of Sound and Vibration 42, 219-234.

Lee, L., Allen, D., 2010. Vibration frequency and lock-in bandwidth of tensioned, flexible cylinders experiencing vortex shedding. Journal of Fluids and Structures 26, 602-610.

Lie, H., Larsen, C.M., Vandiver, J.K., 1997. Vortex induced vibrations of long marine risers; model test in a rotating rig. In: Proceedings of the 16th International Conference on Offshore Mechanics and Arctic Engineering, Yokohama, Japan.

Lie, H., Kaasen, K.E., 2006. Modal analysis of measurements from a large-scale VIV model test of a riser in linearly sheared flow. Journal of Fluids and Structures 22, 557-575.

Lucor, D., Triantafyllou, M.S., 2008. Parametric study of a two degree-of-freedom cylinder subject to vortex-induced vibrations. Journal of Fluids and Structures 24, 1284-1293.

Marcollo, H., Hinwood, J.B., 2006. On shear flow single mode lock-in with both cross-flow and in-line lock-in mechanisms. Journal of Fluids and Structures 22, 197-211.

Mathelin, L., de Langre, E., 2005. Vortex-induced vibrations and waves under shear flow with a wake oscillator model. European Journal of Mechanics B-Fluids 24 (4), 478-490.

Modarres-Sadeghi, Y., Mukundan, H., Dahl, J.M., Hover, F.S., Triantafyllou, M.S., 2010. The effect of higher harmonic forces on fatigue life of marine risers Journal of Sound and Vibration 329, 43-55.

Morse, T.L., Williamson, C.H.K., 2006. Employing controlled vibrations to predict fluid forces on a cylinder undergoing vortex-induced vibration. Journal of Fluids and Structures 22, 877-884.

Morse, T.L., Williamson, C.H.K., 2009. Prediction of vortex-induced vibration response by employing controlled motion. Journal of Fluid Mechanics 634, 5-39.

Mukundan, H., Modarres-Sadeghi, Y., Dahl, J.M., Hover, F.S., Triantafyllou, M.S., 2009. Monitoring VIV fatigue damage on marine risers. Journal of Fluids and Structures 25, 617-628.

Newman, D.J., Karniadakis, G.E., 1997. A direct numerical simulation study of flow past a freely vibrating cable. Journal of Fluid Mechanics 344, 95-136.

Païdoussis, M.P., Price, S.J., de Langre, E., 2011. In: Fluid-Structure Interactions: Cross-Flow-Induced InstabilitiesCambridge University Press, New York

Pontaza, J.P., Chen, H.C., 2007. Three-dimensional numerical simulations of circular cylinders undergoing two degree-of-freedom vortex-induced vibrations. Journal of Offshore Mechanics and Arctic Engineering 129, 158-164.

Pontaza, J.P., Menon, R.G., Chen, H.C., 2009. Three-dimensional numerical simulations of flows past smooth and rough/bare and helically straked circular cylinders allowed to undergo two degree-of-freedom motions. Journal of Offshore Mechanics and Arctic Engineering $131,021301$.

Sanchis, A., Saelevik, G., Grue, J., 2008. Two-degree-of-freedom vortex-induced vibrations of a spring-mounted rigid cylinder with low mass ratio. Journal of Fluids and Structures 24, 907-919.

Sarpkaya, T., 1995. Hydrodynamic damping, flow-induced oscillations, and biharmonic response. Journal of Offshore Mechanics and Arctic Engineering $117,232-238$.

Sarpkaya, T., 2004. A critical review of the intrinsic nature of vortex-induced vibrations. Journal of Fluids and Structures $19,389-447$.

Skop, R.A., Griffin, O.M., 1973. A model for the vortex-excited resonant response of bluff cylinders. Journal of Sound and Vibration $27,225-233$.

Skop, R.A., Balasubramanian, S., 1997. A new twist on an old model for vortex-excited vibrations. Journal of Fluids and Structures $11,395-412$.

Srinil, N., 2010. Multi-mode interactions in vortex-induced vibrations of flexible curved/straight structures with geometric nonlinearities. Journal of Fluids and Structures 26, 1098-1122.

Sumner, D., 2010. Two circular cylinders in cross-flow: a review. Journal of Fluids and Structures 26, 849-899.

Tognarelli, M.A., Slocum, S.T., Frank, W.R., Campbell, R.B., 2004. VIV response of a long flexible cylinder in uniform and linearly sheared currents. In: Proceedings of the Offshore Technology Conference, OTC 16338, Houston.

Triantafyllou, M.S., 2003. VIVA Extended User's Manual. Massachusetts Institute of Technology, Department of Ocean Engineering, Cambridge, MA, USA

Trim, A.D., Braaten, H., Lie, H., Tognarelli, M.A., 2005. Experimental investigation of vortex-induced vibration of long marine risers. Journal of Fluids and Structures 21, 335-361.

Vanatta, C.W., Gharib, M., 1987. Ordered and chaotic vortex streets behind circular-cylinders at low Reynolds-numbers. Journal of Fluid Mechanics $174,113-133$.

Vandiver, J.K., 1993a. Drag coefficients of long flexible cylinders. OTC, 1983.

Vandiver, J.K., 1993b. Dimensionless parameters important to the prediction of vortex-induced vibration of long, flexible cylinders in ocean currents. Journal of Fluids and Structures 7, 423-455.

Vandiver, J.K., Allen, D., Li, L., 1996. The occurrence of lock-in under highly sheared conditions. Journal of Fluids and Structures 10 , 555-561.

Vandiver, J.K., 1999. User Guide for SHEAR7. Massachusetts Institute of Technology, Department of Ocean Engineering, Cambridge, MA, USA.

Vandiver, J.K., Jaiswal, V., Jhingran, V., 2009. Insights on vortex-induced, traveling waves on long risers. Journal of Fluids and Structures $25,641-653$.

Violette, R., de Langre, E., Szydlowski, J., 2007. Computation of vortex-induced vibrations of long structures using a wake oscillator model: comparison with DNS and experiments. Computers \& Structures 85, 1134-1141.

Violette, R., de Langre, E., Szydlowski, J., 2010. A linear stability approach to vortex-induced vibrations and waves. Journal of Fluids and Structures 26, 442-466.

Wang, X.Q., So, R.M.C., Chan, K.T., 2003. A non-linear fluid force model for vortex-induced vibration of an elastic cylinder. Journal of Sound and Vibration 260, 287-305.

Williamson, C.H.K., Govardhan, R., 2004. Vortex-induced vibrations. Annual Review of Fluid Mechanics 36, $413-455$.

Wu, X.D., Ge, F., Hong, Y.S., 2010 Effect of traveling wave on vortex-induced vibrations of submerged floating tunnel tethers. In: Proceedings of 1 st International Symposium on Archimedes Bridge, vol. 4, pp. 153-160.

Yamamoto, C.T., Meneghini, J.R., Saltara, F., Fregonesi, R.A., Ferrari, J.J., 2004. Numerical simulations of vortex-induced vibration on flexible cylinders. Journal of Fluids and Structures 19, 467-489.

Zhang, L., Chen, W., Zheng, Z., 2010. Controlling parameter for wave types of long flexible cable undergoing vortex-induced vibration. Proceedings of 1st International Symposium on Archimedes Bridge 4, 161-170. 